\title{
Inhibition or Facilitation? A Review of Research on the Effects of Uncertainty Stimuli on User Psychology and Behavior
}

\author{
Hui Xu*, Zhiwu Chen, Jian Mao \\ School of Economic and Management, Shanghai Maritime University, Shanghai, China \\ Email: *xuhui190@126.com
}

How to cite this paper: $\mathrm{Xu}, \mathrm{H}$., Chen, $\mathrm{Z}$. W., \& Mao, J. (2020). Inhibition or Facilitation? A Review of Research on the Effects of Uncertainty Stimuli on User Psychology and Behavior. American Journal of Industrial and Business Management, 10, 1586-1604. https://doi.org/10.4236/ajibm.2020.109101

Received: August 11, 2020

Accepted: September 20, 2020

Published: September 23, 2020

Copyright $\odot 2020$ by author(s) and Scientific Research Publishing Inc. This work is licensed under the Creative Commons Attribution International License (CC BY 4.0).

http://creativecommons.org/licenses/by/4.0/

(c) $\underset{\mathrm{By}}{\text { (i) Open Access }}$

\begin{abstract}
The uncertainty stimulus likes a double-edged sword that affects the user's psychology and behavior. On the one hand, people generally have a tendency to avoid uncertainty, so uncertainty stimulus will hinder people's decision of buying behavior; On the other hand, researchers have found that the appropriate use of uncertain stimulus can prompt users to make purchase behavior decisions. Based on the theoretical research and business practice, this paper systematically sorts out the related research of nearly 30 years, and comprehensively reviews the research on the influence effect of uncertain stimulus from the perspective of user psychology and behavior. More specifically, this paper basically answers three questions about the core issues of uncertainty: "What is a valid form of uncertain stimulus", "Why does uncertain stimulus effective", "How does the effect of uncertainty stimulus change". Finally, by constructing the model of the relationship between the uncertain stimulus and the user's psychology and behavior, this paper points out the main characteristics of the existing research and the future research direction, so as to provide reference for the follow-up research on the research of uncertainty.
\end{abstract}

\section{Keywords}

Uncertainty Stimulus, User Psychology, Consumption Behavior, Incentive Mechanism, Gamification

\section{Introduction}

Whether it is "The black swan" (Taleb, 2007) or "The gray rhino" (Wucker, 2016), many behavioral decisions made by users are based on the possibility of an uncertain stimulus (Tversky \& Kahneman, 1982). The role of uncertainty stimuli is two-sided. On one hand, there are uncertainty stimuli that people avoid 
(Gneezy et al., 2006). For example, uncertainty of economic development due to novel coronavirus in 2020, uncertainty of earnings due to stock market risk, etc. (Taleb, 2007; Wucker, 2016). On the other hand, there are uncertainty stimuli that people pursue (Abuhamdeh et al., 2015). For example, Raffles held by merchants, blind box products, etc. (Goldsmith \& Amir, 2010; Xu \& Dukes, 2019).

As early as the 1920s, academics began to conduct systematic research on uncertainty stimuli (Knight, 2012). Classical theories of behavioral decision making such as "Expected utility theory", "Prospect theory", and "Uncertainty effect" all argue that users are risk averse (Tversky \& Kahneman, 1979; Von Neumann \& Morgenstern, 1944; Gneezy et al., 2006), so that the greater the uncertainty stimulus, the more likely the user is to make behavioral decisions such as avoidance and abandonment, etc. (Wu, 1999; Gao \& Gudykunst, 1990; Buhr \& Dugas, 2002). Therefore, in order to increase transaction success rates, merchants often provide more information through product packaging, labeling and even virtual reality (VR) technology to eliminate uncertainty concerns for users and investors (Kostis \& Ritala, 2020; Sielicka-Różyńska et al., 2020; Lye et al., 2020). However, in the 21st century, a growing number of researchers have found that uncertainty stimuli exhibit unexpectedly positive effects, especially when applied them to commercial activities (Ruan et al., 2018; Shen et al., 2018; Hill et al., 2016; Sevilla \& Meyer, 2020; Guo et al., 2019; Moon \& Nelson, 2019). Rather than leading to user aversion, the appropriate use of uncertainty stimuli enables firms to motivate users' decision in a more cost-effective manner (Goldsmith \& Amir, 2010; De Vries \& Zhang, 2020; Nuryakin \&Munro, 2019), or promote without compromising the brand image (Tan et al., 2019). Therefore, the two-sided nature of the effect of uncertain stimulus effects is an important issue to investigate.

Existing related studies focus on business decisions and strategies under uncertainty stimuli (Bonaime et al., 2018), less systematic and comprehensive examination of the utility of uncertainty stimuli from the perspective of user behavior, and most studies have focused singularly on the effects of uncertainty stimuli positively (Hsee \& Ruan, 2016; Gaertig, 2019) or negatively (Gneezy et al., 2006), lacking a comparative study of the two-sided nature of the effects of uncertainty stimuli. To fill this gap, this paper mainly synthesizes relevant research in the past 30 years to systematically sort out the two-sided role of uncertainty stimuli from the perspective of user psychology and behavior and to suggest the future research direction of uncertainty stimuli. To summarize, this paper mainly answers the following three questions: what are the effective forms of uncertainty stimuli? Why do uncertainty stimuli work? How does uncertainty stimulus work?

\section{What Is a Valid Form of Uncertainty Stimulus?}

\subsection{Implications of Uncertainty Stimuli}

Uncertainty refers to both the variability and unpredictability of future events (Taleb, 2007) and the cognitive state that individuals are in due to the presence 
of unknown information (Loewenstein, 1994). Uncertainty manifests itself in different ways for different user involvement contexts (Goldsmith \& Amir, 2010; Abuhamdeh et al., 2015; Whitchurch et al., 2011) (see Table 1).

Table 1 summarizes the effective forms of uncertainty and their theoretical supports. Uncertainty stimulus is closely related to the context in which the users finds themselves, specifically including uncertainty gains or uncertainty losses faced by individuals or firms in economic decision making (Von Neumann \& Morgenstern, 1944; Tversky \& Kahneman, 1979); uncertainty promotions used by businesses (Laran \& Tsiros, 2013); competitive uncertain outcomes in competitions (Abuhamdeh et al., 2015); uncertain rewards in corporate incentives for employees or sweepstakes (Shen et al., 2018), and so on. Although the effective forms of uncertainty are diverse, their causes can be essentially summarized in two categories: the probabilistic perspective and the informational perspective.

The probability perspective is the mathematical and statistical view that uncertainty is linked to the probability of the outcome of an event (Laran \& Tsiros, 2013). In existing research, some scholars do not explicitly give outcome probabilities in their studies, i.e., they create uncertainty through fuzzy probabilities (Goldsmith \& Amir, 2010; Shen et al., 2018); other group of scholars studied users' psychological and behavioral responses at different probability values by manipulating specific probabilities to influence subjects' perceptions of uncertainty stimuli (Shen et al., 2014; Laran \& Tsiros, 2013).

The informational perspective refers to uncertainty due to lack of information and limited knowledge (Hsee \& Ruan, 2016; Hill et al., 2016; Ruan et al., 2018). "Information gap theory" is widely accepted in psychological research (Hsee \& Ruan, 2016). The information gap is the gap between what a person "already knows" and what he or she "wants to know" (Loewenstein, 1994), and this gap leads to uncertainty about the final outcome (Ruan et al., 2018). Thus, hiding information is a good way to create uncertainty. For example, in commerce, many businesses will keep information about new products confidential to attract consumer attention (Hill et al., 2016).

\subsection{The Two Sides of the Uncertainty Stimulus}

Although scholars have defined uncertainty stimuli from different perspectives and have produced a number of research results, there is still no conclusive answer as to whether uncertainty stimuli inhibit or facilitate user behavior.

Under the "homo economicus" perspective, traditional theories focus on economic outcomes, arguing that people are risk-averse and tend to avoid uncertainty. Psychologically, uncertainty stimuli tend to bring negative emotions (Gao \& Gudykunst, 1990; Wu, 1999; Buhr \& Dugas, 2002), furthermore, these negative emotions accompany the various stages of uncertainty (Gordon, 2003). Firstly, people feel stressed in the face of uncertainty (Gao \& Gudykunst, 1990). Secondly, if the uncertainty cannot be resolved quickly, people reveal their worry and feel anxious ( $\mathrm{Wu}, 1999)$. Finally, when people learn that they have made a 
wrong choice, they will have further feelings of regret and frustration (Mandel \& Nowlis, 2008). Behaviorally, expected utility theory argues that in the presence of risky outcomes, such as gambling, lottery and insurance, the higher an individual's risk aversion, the lower the expected utility, and the more likely they are to reject outcomes with high uncertainty (Rabin, 2000). Prospect theory further demonstrating that people prefer certainty over uncertainty gains (Von Neumann \& Morgenstern, 1944). Moreover, the expected utility of an uncertain outcome may even be lower than the expected utility of the worst outcome (Gneezy et al., 2006).

Table 1. Effective forms of uncertainty and their causes.

\begin{tabular}{|c|c|c|c|c|}
\hline Forms & Representative studies & Causation & Theoretical foundation & Main ideas \\
\hline \multirow{2}{*}{$\begin{array}{l}\text { Uncertainty } \\
\text { gains }\end{array}$} & $\begin{array}{l}\text { Von Neumann \& } \\
\text { Morgenstern (1944) }\end{array}$ & probability & expected utility theory & $\begin{array}{l}\text { Human beings are absolutely rational and seek to } \\
\text { maximize expected utility }\end{array}$ \\
\hline & Gneezy et al. (2006) & probability & uncertainty effect & $\begin{array}{l}\text { Users evaluate the uncertainty stimulus even lower } \\
\text { than the worst outcome }\end{array}$ \\
\hline \multirow{6}{*}{$\begin{array}{l}\text { Uncertainty } \\
\text { promotions }\end{array}$} & $\begin{array}{l}\text { Goldsmith \& Amir } \\
\text { (2010) }\end{array}$ & probability & optimism & $\begin{array}{l}\text { No significant difference in effect between } \\
\text { uncertainty and certainty promotions }\end{array}$ \\
\hline & Laran \& Tsiros (2013) & $\begin{array}{l}\text { Probability; } \\
\text { Information gap }\end{array}$ & $\begin{array}{l}\text { positive emotional } \\
\text { experiences }\end{array}$ & $\begin{array}{l}\text { When the user is rational, the uncertainty stimulus } \\
\text { inhibits consumption; when the user is emotional, the } \\
\text { uncertainty stimulus promotes consumption }\end{array}$ \\
\hline & Shen et al. (2014) & probability & $\begin{array}{l}\text { positive emotional } \\
\text { experiences }\end{array}$ & $\begin{array}{l}\text { When users focus on the process, the positive } \\
\text { experience generated by the uncertainty incentive } \\
\text { motivates them to commit more resources }\end{array}$ \\
\hline & Hill et al. (2016) & Information gap & curiosity & $\begin{array}{l}\text { By creating a sense of mystery, merchants can engage } \\
\text { the user's curiosity and motivate purchase }\end{array}$ \\
\hline & Mazar et al. (2016) & probability & diminishing sensitivity & $\begin{array}{l}\text { In the case of equal expectations, the uncertainty } \\
\text { stimulus not only motivates users to buy, but to buy } \\
\text { more }\end{array}$ \\
\hline & Ruan et al. (2018) & Information gap & curiosity & $\begin{array}{l}\text { The process of creating and resolving uncertainty } \\
\text { leads to an enjoyable experience for the user and a } \\
\text { positive brand perception }\end{array}$ \\
\hline \multirow{3}{*}{$\begin{array}{l}\text { Uncertainty } \\
\text { results }\end{array}$} & Vosgerau et al. (2006) & Information gap & $\begin{array}{l}\text { positive emotional } \\
\text { experiences }\end{array}$ & $\begin{array}{l}\text { Even if you don't know the end result beforehand, } \\
\text { watching a replay is far less exciting than watching it } \\
\text { live }\end{array}$ \\
\hline & Norton et al. (2007) & Information gap & ambiguity & $\begin{array}{l}\text { Ambiguity in relationships creates more likeable } \\
\text { emotions }\end{array}$ \\
\hline & Whitchurch et al. (2011) & Information gap & $\begin{array}{l}\text { positive emotional } \\
\text { experiences }\end{array}$ & $\begin{array}{l}\text { Women will find men who are unclear about their } \\
\text { attitudes more attractive }\end{array}$ \\
\hline $\begin{array}{l}\text { Uncertainty } \\
\text { rewards }\end{array}$ & Shen et al. (2018) & probability & $\begin{array}{l}\text { positive emotional } \\
\text { experiences }\end{array}$ & $\begin{array}{l}\text { Resolving uncertainty as a mental reward will } \\
\text { motivate repetitive user behavior }\end{array}$ \\
\hline
\end{tabular}

Source: Based on relevant literature. 
Unlike traditional decision models that focus on economic outcomes, in the last decade researchers have focused more on the spiritual enjoyment of uncertainty (Loewenstein, 1994; Shen et al., 2018). Psychologically, uncertainty stimuli can lead to positive affective experiences such as suspense, fun, and excitement. Vosgerau et al. (2006) and Abuhamdeh et al. (2015) found that people enjoy the excitement and suspense brought about by uncertainty in activities such as live television and competitive gaming. Laran \& Tsiros (2013) found that people interested in uncertainty promotion. Whitchurch et al. (2011) and Norton et al. (2007) point out knowing more about people or things conversely makes people or things less attracted to others. Behaviorally, Goldsmith \& Amir (2010) were the first to experimentally demonstrate the positive effects of uncertainty promotions, finding that consumers had equal purchase intentions for uncertainty promotions (a pack of chocolate truffles or two chocolate bars) and certainty promotions (a pack of chocolate truffles). Mazar et al. (2016) further demonstrated through mathematical modeling that under equal expectations uncertainty promotions have better utility. Shen et al. (2014, 2018) successively suggest that uncertainty stimuli can enhance people's resource investment in the process and repetitive behavior. Hsee \& Ruan (2016) even find that people will act to address uncertainty even when negative outcomes are expected.

\section{Why Are Uncertainty Stimuli Effective?}

By outlining the effective forms of uncertainty stimuli, it can be found that research on the effective effects of uncertainty stimuli can be roughly divided into two stages: the first stage (1920s-1990s) scholars generally believe that uncertainty stimuli have an inhibitory effect on user behavior. In the second stage (1990s-present), scholars are increasingly concerned about the facilitative effect of uncertainty stimuli on user behavior. The mechanisms by which uncertainty stimuli inhibit or facilitate user psychology and behavior will be further explored in this section to explain why uncertainty stimuli are effective.

\subsection{Inhibition Mechanisms of Uncertainty Stimuli on User Psychology and Behavior}

The mechanism of the inhibitory effect of uncertainty stimuli on user psychology and behavior can be explained by both cognitive and affective mechanisms.

\subsubsection{Cognitive Mechanisms}

Cognition refers specifically to the knowledge, beliefs, and values that guide an individual's behavior a specific situation (Homer \& Kahle, 1988). The "rational person" is an important assumption of behavioral economics, which holds that individuals make decisions taking into account the value of all outcomes and their probabilities, and then seek to maximize the expected value (Von Neumann \& Morgenstern, 1944). In this cognitive perspective, expected utility theory, prospect theory and uncertainty effect all suggest that uncertain stimuli will reduce the user's assessment of uncertainty benefits, thus exhibiting risk 
aversion in behavior.

Expected utility theory (Von Neumann \& Morgenstern, 1944) lays down the basic form of the expected utility function.

$$
U=\sum_{i=1}^{n} p_{i} u\left(x_{i}\right)
$$

where, $u\left(x_{i}\right)$ and $p_{i}$ respectively represent the expected value of the outcome of the event and the probability of its occurrence. The theory holds that the utility function $U$ is concave and has decreasing marginal utility, so the expected value of the user will be lower than that of the deterministic event.

Prospect theory further finds that when the expected utility is equal or even higher with uncertainty, most people will still choose the certainty benefits, that is the certainty effect (Tversky \& Kahneman, 1979). Unlike expected utility theory, prospect theory holds that probability $p$ is also a function $I I(p)$, and proves that $I I(p)+I I(1-p)<1$. It can be seen from this:

$$
I I(p) * u\left(x_{1}\right)+I I(1-p) * u\left(x_{2}\right)<p * u\left(x_{1}\right)+(1-p) * u\left(x_{2}\right)
$$

Thus, the expected value of the user will be lower in prospect theory than in expected utility theory.

Expected utility theory and prospect theory both argue that the expected utility of an uncertainty event lies between the best and worst outcome expectations. However, in complex decision situations, Gneezy et al. (2006) found that people underestimate uncertainty gains, even below the expectations of the worst outcome, referring to this phenomenon as the uncertainty effect, where the uncertainty stimulus leads to a cognitive bias that unreasonably underestimates uncertainty gains, thus making users prefer certainty gains over uncertainty gains.

\subsubsection{Affective Mechanisms}

Emotions are subjective feelings and states of an individual that can significantly affect cognition and behavior such as memory and how information is processed (Kaufmann G, 2003). According to the traditional theory, uncertainty stimuli will bring negative emotions such as fear, frustration and worry to the user, which in turn will inhibit the user's behavior (Wu, 1999). Gao \& Gudykunst (1990); Buhr \& Dugas (2002) pointed out that in the influence of uncertainty stimuli, the inhibitory effects of "anxiety" and "regret" are particularly significant.

Anxiety is the user's concern about uncertain outcomes (MacLeod et al., 1991). Wu (1999) argues that anxiety creates an additional psychological burden on users and causes them to overestimate the probability of poorer outcomes and therefore needs to be included in the decision model. Regret is a negative feeling when one realizes that other choices might have turned out better (Loomes \& Sugden, 1982), and can be divided into "expected regret" and "experienced regret". Expected regret stems from the user's imagination of the consequences of a potential failure, so that predictive behavior instead impairs the us- 
er's own experience (Mandel \& Nowlis, 2008). Experience regret is the negative experience of the outcome of a wrong decision (Raeva et al., 2010). In conclusion, the affective mechanism perspective recognizes that uncertainty inhibits user behavior because it brings negative feelings such as anxiety and regret.

\subsection{Facilitation Mechanisms of Uncertainty Stimuli on User Psychology and Behavior}

The mechanism of the facilitative effect of uncertainty stimuli on user psychology and behavior can also be explained by both cognitive and affective mechanisms.

\subsubsection{Cognitive Mechanisms}

"Innate optimism theory" and "Information gap theory" are two key theories from the cognitive perspective to explain the facilitative effect of uncertainty stimuli on user behavior.

Innate optimism theory holds that people's subjective probabilities tend to be higher than their actual probability values, which is a cognitive bias due to individual cognitive bureaucracy. It mainly includes the following three aspects: First, overly positive self-evaluations. It refers to the fact that most people have a positive view of themselves (Greenwald, 1980), and that highly distorted evaluations of one's own character and abilities tend to bias individuals' judgments of uncertainty stimuli (Taylor \& Brown, 1988). In fact, it is the same as people want to believe that "good things come to those who do good things" (Lerner, 1965). Therefore, overly positive self-evaluation will eliminate users' aversion to risks and they can expect to get the optimal results. Second, control illusion. It argues that users often believe that random events are controllable when confronted with uncertain stimuli (Presson et al., 1996). Research has shown that people's beliefs about personal control sometimes go beyond what is reasonable (Taylor \& Brown, 1988). Third, unrealistic optimism. It argues that people overestimate the probability of an outcome they expect or underestimate the probability of an outcome they do not expect (Ailawadia et al., 2014). In the case of uncertainty promotions, for example, users are confident that they will get the highest discounts (Dhar et al., 1999), draw the best prizes (Goldsmith \& Amir, 2010) or get a chance to get a free ticket (Mazar et al., 2016). Thus, uncertainty stimulus can act as a motivator through users' optimistic perceptions.

Different form optimism theories which are concerned with the outcome of uncertainty stimuli, information gap theory places more emphasis on process (Hsee \& Ruan, 2016; Ruan et al., 2018). The information gap theory reveals that when users pay attention to their existing knowledge gap, uncertainty will lead to the information gap and the ensuing sense of curiosity (Loewenstein, 1994). And curiosity is considered a key motivating factor that drives people's behavior. The information gap theory agrees that curiosity is a negative state that people act to eliminate (Jones et al., 1961; Frisch \& Baron, 1988). Recently, the role of curiosity in business research and practice has also received increasing attention, 
as Hill et al. (2016) show that "mystery" is a powerful sales tool for retailers and can stimulate consumers' willingness to purchase. Ruan et al. (2018) also demonstrated experimentally that the use of uncertainty stimuli in advertising campaigns can be effective in enhancing brand image and user favorability.

\subsubsection{Affective Mechanisms}

A large body of marketing literature has demonstrated that positive emotions can promote user purchase behavior (Strack \& Deutsch, 2006; White \& McFarland, 2009). Also based on the focus on the process of uncertainty stimuli, recent research has found that uncertainty brings a host of positive emotional experiences, including surprise, fun and pleasure, and ultimately contribute to user behavior.

Laran \& Tsiros (2013) demonstrated that uncertainty promotions in emotional decision making can evoke multiple positive emotions, mainly through fun to improve consumers' willingness to purchase. Shen et al. (2014) proved that uncertain rewards can bring excitement to users, so users invest more resources, including time, money and effort, in the process of pursuing uncertain rewards. Shen et al. (2018) also found that when users resolve uncertainty, they will get a kind of spiritual reward. Compared with simple material reward, users prefer the pleasure of resolving uncertainty and more likely to adopt repetitive behaviors.

Above all, the mechanism of the effect of uncertainty stimuli on user psychology and behavior is summarized in Table 2. Specifically, the uncertainty stimuli affect user behavior primarily through cognitive and affective mechanisms. When users focus on economic outcomes, uncertainty tends to stimulate negative emotions and behaviors as an inhibition effect; when users overestimate the probability of the optimal outcome out of optimism, or out of curiosity and the pleasure of the uncertainty process, uncertainty can be facilitated by positive emotional experiences.

\section{How Does the Effect of Uncertainty Stimulus Change?}

The question of how does the effect of uncertainty stimulus change answers the utility boundaries of the uncertainty stimulus. The mechanism of effect of an uncertain stimulus is composed of two core elements. One is the uncertain stimulus itself, which is the subject of the mechanism, and its effect is related to its type and characteristics; the other is the user, which is the object of the mechanism, and its effect is related to the user's behavioral characteristics. Therefore, when discussing how the effects of an uncertain stimulus change, the following three points are the main focus: the type of uncertain stimulus, the characteristics of the uncertain stimulus, and the characteristics of the user.

\subsection{Types of Uncertainty Stimuli}

Based on the division of potential benefits, the uncertainty stimuli can be divided into positive and negative uncertainty (Wilson et al., 2005; Bar-Anan et al., 2009). 
Table 2. Mechanisms of the effect of uncertainty stimuli on user psychology and behavior.

\begin{tabular}{|c|c|c|c|}
\hline Effect & Mechanisms & Theory & Representative studies \\
\hline \multirow{7}{*}{ Inhibition } & \multirow{3}{*}{ Cognitive } & Expected utility theory & Von Neumann \& Morgenstern, 1944 \\
\hline & & Prospect theory & Tversky \& Kahneman, 1979 \\
\hline & & Uncertainty effect & Gneezy et al., 2006 \\
\hline & \multirow{4}{*}{ Affective } & \multirow[t]{2}{*}{ Anxiety } & MacLeod et al., 1991 \\
\hline & & & Wu, 1999 \\
\hline & & \multirow[t]{2}{*}{ Regret } & Loomes \& Sugden, 1982 \\
\hline & & & Mandel \& Nowlis, 2008 \\
\hline \multirow{10}{*}{ Facilitation } & \multirow{7}{*}{ Cognitive } & Overly positive self-evaluations & Greenwald, 1980 \\
\hline & & & Lerner, 1965 \\
\hline & & Control illusion & Presson et al., 1996 \\
\hline & & Unrealistic optimism & Ailawadia et al., 2014 \\
\hline & & & Dhar et al., 1999 \\
\hline & & Information gap theory & Loewenstein, 1994 \\
\hline & & & Ruan et al., 2018 \\
\hline & \multirow{3}{*}{ Affective } & Suspense & Abuhamdeh et al., 2015 \\
\hline & & Interesting & Shen et al., 2018 \\
\hline & & Excitement & Shen et al., 2014 \\
\hline
\end{tabular}

Source: Based on relevant literature.

Positive uncertainty is uncertainty associated with positive events (e.g., unknown gifts, shopping mall raffles, etc.) (Wilson et al., 2005; Lee \& Qiu, 2009). Conversely, negative uncertainty is associated with negative events (e.g., unexpected losses) (Tversky \& Kahneman, 1979). Positive events are favorable in general, then positive uncertainty can positively stimulate user behavior by making the user imagine the prospect and evoking a positive affective experience (Wilson et al., 2005; Bar-Anan et al., 2009; Faraji-Rad \& Pham, 2017). However, negative events are often worrisome, and its uncertainty amplifies the many negative emotions that can inhibit user behavior (Calvo \& Castillo, 2001).

\subsection{Characteristics of Uncertainty Stimuli}

The characteristics of the uncertainty stimulus focus on the degree of uncertainty and the likelihood that it will be resolved.

\subsubsection{Degree of Uncertainty Stimulus}

"Moderate" uncertainty stimuli are most effective in motivating users (Loewenstein, 1994; Hill et al., 2016; Hsee \& Ruan, 2016). How to define "moderate"? 
From a probabilistic perspective, most of the literature suggests that uncertainty stimuli are most effective when the probability of each outcome is equal, that is, when uncertainty is highest (Hill et al., 2016; Shen et al., 2014). In competitive matches, Abuhamdeh et al. (2015) demonstrate that users prefer to participate in an evenly matched match, when the scores are close and the uncertainty of the outcome is highest. In terms of the information gap, too high uncertainty (i.e., large information gap) will only confuse people, but too low uncertainty (i.e., small information gap) will not attract users' attention (Loewenstein, 1994). Therefore, researchers will also seek to find an appropriate point to control for the amount of information stimulated by uncertainty (Hill et al., 2016).

\subsubsection{Whether the Uncertainty Stimulus Can Be Resolved}

There are two accounts of the impact of whether uncertainty can be resolved or not. Traditional economic decision theory suggests that users tend to resolve uncertainty quickly, and are even willing to lose some gain for it (Wu, 1999). Thus, uncertainty that can be resolved quickly works better (Shen et al., 2018). Modern psychological theories, however, argue that although uncertainty has the expectation that it can be resolved, which increases its positive utility (Kruk et al., 2004), it does not have to be resolved quickly. Because uncertainty offers the potential to create positive experiences (Ruan et al., 2018), and because the appeal of uncertainty stimuli is in the process of creation and resolution, an appropriate delay in resolving uncertainty can provide the user with room for imagination (Chew \& Ho, 1994; Loewenstein, 1994) and can also have a positive impact (Chew \& Ho, 1994; Hill et al., 2016).

\subsection{User Characteristics}

First of all, the more rational users are concerned more with economic benefits, and in most cases uncertainty stimuli are not economically optimal (Gneezy et al., 2006; Goldsmith \& Amir, 2010), so rational people are avoidant of uncertainty stimuli. In other words, uncertainty stimuli are more effective for emotional users (Goldsmith \& Amir, 2010; Laran \& Tsiros, 2013; Shen et al., 2014). Second, Laran \& Tsiros (2013) argue that the key to determining whether the impact utility of an uncertainty stimulus is inhibited or facilitated depends on if the user's decision contains emotion or not. They propose a decision framework: in emotional decisions, uncertainty is beneficial; in cognitive decisions, uncertainty is harmful. This is because uncertainty in emotional decisions gives people a greater sense of surprise (Laran \& Tsiros, 2013), whereas uncertainty in cognitive decisions gives people less information (Loewenstein, 1994). Thirdly, whether users are outcome-focused or process-focused also affects the impact utility of uncertainty stimuli. The more the users focus on the outcome of the uncertainty stimulus rather than the process, the less effective the uncertainty stimulus will be. Users who focus on the process are more likely to experience the positive experience that the uncertainty stimulus can provide (Le Menestrel, 2001; Shen et al., 2014). 


\section{Conclusion and Future Research Direction}

\subsection{Findings of the Research}

Through a systematic literature review and summary, this paper answers three fundamental questions about uncertainty stimuli: what, why, and how. The basic logic of these three questions is shown in Figure 1.

To answer the question "what is a valid form of uncertain stimulus", the main forms of uncertainty stimulus have been explored, which includes uncertainty losses, uncertainty gains, uncertainty promotions, uncertainty results and uncertainty rewards. It can be acted as independent variables in the uncertainty mechanism (Goldsmith \& Amir, 2010; Laran \& Tsiros, 2013). To answer the question "why does uncertain stimulus effective", the influence mechanism of uncertainty stimuli have been analyzed. Specifically, uncertainty stimulus act as a double-edged sword on user behavior through cognitive and affective mechanisms (Wu, 1999; Mandel \& Nowlis, 2008; Goldsmith \& Amir, 2010; Ruan et al., 2018). To answer the question "how does the effect of uncertainty stimulus change", the utility boundaries of uncertainty stimulus have been discussed. To be specific, it includes user characteristics, types and characteristics of uncertainty stimulus, which can be acted as moderators in the research framework. (Laran \& Tsiros, 2013; Wilson et al., 2005; Hill et al., 2016; Ruan et al., 2018).

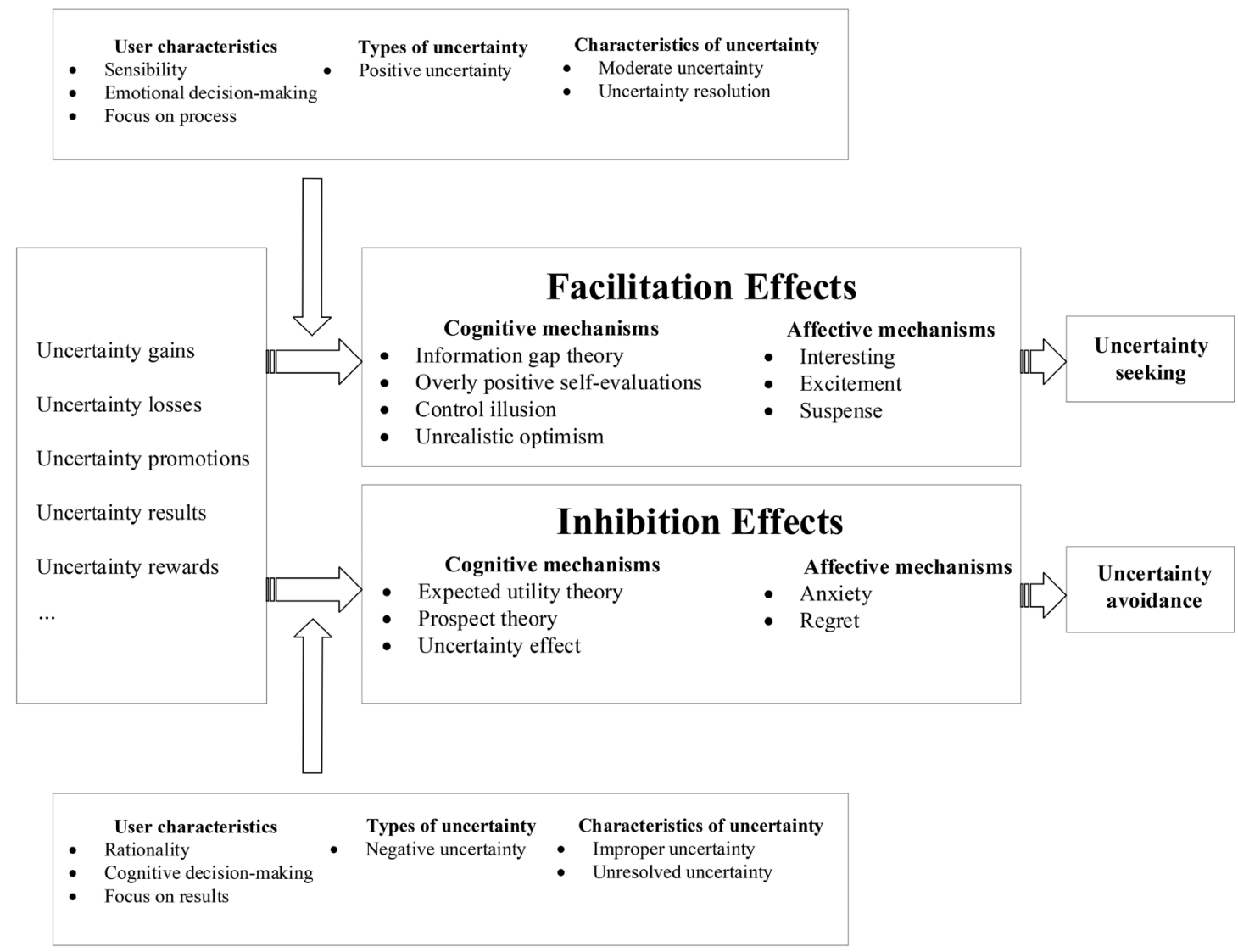

Figure 1. Integration framework for the psychological and behavioral effects of uncertainty stimuli on users. 


\subsection{Business Practice}

First, uncertainty stimulus exist in a variety of valid forms such as uncertainty gains, uncertainty promotions and uncertainty rewards, which are highly relevant to the context in which they are applied (Gneezy et al., 2006; Mazar et al., 2016; Shen et al., 2018). Therefore, companies should consider the diversity of forms when using uncertainty stimulus and use a combination of uncertainty incentives depending on the purpose and context. For example, consumers can be motivated to buy the products through a variety of uncertainty stimuli such as blind boxes (lucky bags), probabilistic free price and probabilistic discounts (Nuryakin \& Munro, 2019; Mazar et al., 2016; Laran \& Tsiros, 2013). For the enterprise, employees can also be motivated to work through uncertainty rewards (Shen et al., 2018).

Second, uncertainty stimulus influence user behavior through affective and cognitive mechanisms, where affective mechanisms include user's positive and negative emotional feelings towards uncertainty stimulus (Shen et al., 2018; Wu, 1999; Mandel \& Nowlis, 2008). Uncertainty stimuli have a positive impact on user behavior only when they provide a positive experience for the user. Therefore, companies need to consider users' emotional responses. For example, a company can increase the impact of an uncertainty stimulus by designing the appearance of the stimulus in a way that makes it more appealing to users and increases their positive feelings towards it (Laran \& Tsiros, 2013). Additionally, Cognitive mechanisms refer to the user's mastery of information about the uncertainty stimulus (Loewenstein, 1994; Ruan et al., 2018). Therefore, companies need to consider the user's receptivity to the information generated by the uncertainty stimulus. In practice, firms can increase user curiosity by concealing part of the product information in order to enhance the impact of the stimulus uncertainty (Ruan et al., 2018).

Third, the boundary conditions under which uncertainty stimulates changes in utility can also provide insights into business practice. First of all, compared with rational users, emotional users are more likely to prefer uncertainty stimulus (Laran \& Tsiros, 2013). Therefore, before launching an uncertainty promotion, businesses can carefully study the behavioral characteristics of the target users and adopt an appropriate uncertainty promotion strategy based on the user profile. Secondly, while negative uncertainty is unpopular with consumers, positive uncertainty is like a "Kinder Joy" that offers unknown surprises to consumers. Therefore, businesses can take advantage of users' positive reactions to positive uncertainty and use it in many business promotions. Positive uncertainty rewards can be used to reward users for their participation (reviews, recommendations, sharing, etc.), to increase the sense of surprise and interest in the rewards, and to further increase repeat participation (Ruan et al., 2018). In addition to for-profit projects, many public service activities, such as in "reverse logistics" (Chan et al., 2020), can also attract users to recycle plastic bottles, cardboard boxes and used batteries by using positive uncertainty rewards. Last but 
not least, Moderate uncertainty has the greatest impact utility (Hill et al., 2016; Ruan et al., 2018). Therefore, firms need to consider what constitutes a moderate. For example, when drawing a blind box, when should the consumer know what is in the blind box?

\subsection{Future Research Direction}

\subsubsection{Affective Mechanisms of Uncertainty Stimuli and Their Scale Development}

Affective mechanisms play a crucial mediating role between uncertainty stimuli and user decision behavior, and a growing number of scholars are studying users' psychological feelings (Strack \& Deutsch, 2006; White \& McFarland, 2009; Abuhamdeh et al., 2015). Accurate measurement of positively experienced emotions is fundamental to the study of mediation effect, but there are still no standardized scales among them.

Most of the existing literature roughly mention that users' positive experiences could be the motivation of uncertainty stimuli (Shen et al., 2014; Shen et al., 2018; Ruan et al., 2018), but there is little in-depth discussion on refining the affective dimension. On the one hand, using a holistic concept such as "positive experience" to measure user emotions fails to capture the complex, dynamic and diverse psychological feelings of users in an uncertain environment (Wilson et al., 2005; Hsee \& Ruan, 2016). On the other hand, even if some studies consider specific emotional dimensions, they only measure single dimensions such as "fun," "suspense," and "excitement," which is a biased generalization (Laran \& Tsiros, 2013; Abuhamdeh et al., 2015; Hill et al., 2016). In addition, psychological feelings are quite subjective and dynamic, and current research lacks uniform standards. In summary, future research needs to further develop scales with generalizability and validity based on clarifying and refining the dimensions of user's positive experience, not only to distinguish the importance of a single dimension but also to understand the interactions between the dimensions.

\subsubsection{Focus on Incentives and Penalties for Uncertainty}

From a behavioral perspective, uncertainty stimuli, like traditional incentive theories, emphasize rapid and efficient feedback, and like reinforcement theories that include positive and negative reinforcement (Baker et al., 2004), uncertainty stimuli can likewise be divided into uncertainty rewards and uncertainty punishments. As mentioned earlier, the incentive effect of uncertainty rewards that include a positive outlook is significant (Wilson et al., 2005; Bar-Anan et al., 2009; Lee \& Qiu, 2009), but little literature has discussed the role of uncertainty penalties.

In prospect theory, Tversky \& Kahneman (1979) found that people tend to choose uncertainty losses between certainty and uncertainty losses because the pain of the loss is often greater than the pleasure of receiving the same amount. As a result, uncertainty penalties will be more popular with users (Tversky \& Kahneman, 1992) because optimists will believe that they will draw smaller penalties, and therefore the incentive effect will be less pronounced. In different 
industries, especially in small and medium-sized enterprises (SMEs), where penalties such as fines are an important means for organizations to motivate their employees. Are uncertainty penalties more effective than rewards? This issue is well worth studying.

\subsubsection{The Use of Uncertainty Stimuli in Gamification}

Gamification is the use of game elements to create game-like experiences for users in non-game contexts to influence their motivation and behavior (Morschheuser et al., 2019; Xu et al., 2019). The research on gamification emerged in the field of education and subsequently shone in business fields such as crowdsourcing innovation, employee and user motivation (Feng et al., 2018; Xu, 2020). The main gamification elements used in research and business practice are leaderboards, badges, and points, but these motivational elements are currently only applied in deterministic situations (Faiella \& Ricciardi, 2015). In fact, uncertainty and mystery are both important components of games (Seaborn \& Fels, 2015) and can be a major consideration in gamification design.

Some would mistakenly believe that uncertainty stimuli can only be applied in gambling or gaming situations, or that gamification is a game, which is one-sided (Shen et al., 2018). This paper argues that uncertainty stimuli can also be applied in serious situations, such as advertising campaigns and boring jobs (Ruan et al., 2018). Serious decisions can be made fun through uncertainty stimulation, and it is this ability to make non-gaming situations as enjoyable as gaming situations that is the core content of gamification (Etkin, 2016). Given the high degree of congruence between uncertainty stimuli and gamification, the playful use of uncertainty stimuli should be an important direction for future research that will greatly enrich the theoretical study of uncertainty and gamification.

\subsubsection{Gaining from Uncertainty: Anti-Fragile Stimulus}

Although it has not been established which of the two sides of uncertainty stimulation is stronger or weaker (Shen et al., 2018; Abuhamdeh et al., 2015), the research trend in the past decade shows that scholars are gradually focusing on the positive motivational effect of uncertainty stimulation on users (Shen et al., 2018). However, most of the current research on uncertainty stimuli has been conducted from the perspective of the user as a passive object. Research has focused on detecting how different types of uncertainty stimuli motivate user behavior (Faraji-Rad \& Pham, 2017). Future research could attempt to examine the perspective of users as active subjects and explore what characteristics are characteristic of groups that actively seek and even challenge uncertainty, always succeed in overcoming unexpected uncertainty, and are able to grow against the odds under the pressure of heavy uncertainty risk. These characteristics can be extended from the user to the firm, allowing users and firms to structure their behavior and business models in an anti-fragile manner (Taleb, 2007), thereby increasing their creativity to withstand risk shocks and improve their resilience after a Sudden crisis. This has important implications for the development of real businesses in complex and changing environments. 


\section{Acknowledgements}

This work is supported by the National Natural Science Foundation of China (NSFC) [Project No. 71702100].

\section{Conflicts of Interest}

The authors declare no conflicts of interest regarding the publication of this paper.

\section{References}

Abuhamdeh, S., Csikszentmihalyi, M., \& Jalal, B. (2015). Enjoying the Possibility of Defeat: Outcome Uncertainty, Suspense, and Intrinsic Motivation. Motivation and Emotion, 39, 1-10. https://doi.org/10.1007/s11031-014-9425-2

Ailawadia, K. L., Gedenk, K., Langer, T. et al. (2014). Consumer Response to Uncertain Promotions: An Empirical Analysis of Conditional Rebates. International Journal of Research in Marketing, 31, 94-106. https://doi.org/10.1016/j.ijresmar.2013.08.002

Baker, T. B., Piper, M. E., McCarthy, D. E. et al. (2004). Addiction Motivation Reformulated: An Affective Processing Model of Negative Reinforcement. Psychological Review, 111, 33-51. https://doi.org/10.1037/0033-295X.111.1.33

Bar-Anan, Y., Wilson, T. D., \& Gilbert, D. T. (2009). The Feeling of Uncertainty Intensifies Affective Reactions. Emotion, 9, 123-127. https://doi.org/10.1037/a0014607

Bonaime, A., Gulen, H., \& Ion, M. (2018). Does Policy Uncertainty Affect Mergers and Acquisitions? Journal of Financial Economics, 129, 531-558. https://doi.org/10.1016/j.jfineco.2018.05.007

Buhr, K., \& Dugas, M. J. (2002). The Intolerance of Uncertainty Scale: Psychometric Properties of the English Version. Behaviour Research and Therapy, 40, 931-945. https://doi.org/10.1016/S0005-7967(01)00092-4

Calvo, M. G., \& Castillo, M. D. (2001). Selective Interpretation in Anxiety: Uncertainty for Threatening Events. Cognition \& Emotion, 15, 299-320. https://doi.org/10.1080/02699930126040

Chan, C. K., Man, N., Fang, F. et al. (2020). Supply Chain Coordination with Reverse Logistics: A Vendor/Recycler-Buyer Synchronized Cycles Model. Omega, 95, 102090. https://doi.org/10.1016/j.omega.2019.07.006

Chew, S. H., \& Ho, J. L. (1994). Hope: An Empirical Study of Attitude toward the Timing of Uncertainty Resolution. Journal of Risk and Uncertainty, 8, 267-288. https://doi.org/10.1007/BF01064045

De Vries, E. L. E., \& Zhang, S. (2020). The Effectiveness of Random Discounts for Migrating Customers to the Mobile Channel. Journal of Business Research, 110, 272-281. https://doi.org/10.1016/j.jbusres.2020.01.041

Dhar, S. K., González-Vallejo, C., \& Soman D. (1999). Modeling the Effects of Advertised Price Claims: Tensile versus Precise Claims? Marketing Science, 18, 154-177. https://doi.org/10.1287/mksc.18.2.154

Etkin, J. (2016). The Hidden Cost of Personal Quantification. Journal of Consumer Research, 42, 967-984. https://doi.org/10.1093/jcr/ucv095

Faiella, F., \& Ricciardi, M. (2015). Gamification and Learning: A Review of Issues and Research. Journal of E-Learning and Knowledge Society, 11, 3-17.

Faraji-Rad, A., \& Pham, M. T. (2017). Uncertainty Increases the Reliance on Affect in Decisions. Journal of Consumer Research, 44, 1-21. 
Feng, Y., Ye, H. J., Yu, Y. et al. (2018). Gamification Artifacts and Crowdsourcing Participation: Examining the Mediating Role of Intrinsic Motivations. Computers in Human Behavior, 81, 124-136. https://doi.org/10.1016/j.chb.2017.12.018

Frisch, D., \& Baron, J. (1988). Ambiguity and Rationality. Journal of Behavioral Decision Making, 1, 149-157. https://doi.org/10.1002/bdm.3960010303

Gaertig, C. (2019). Do Consumers Prefer Uncertainty? Consumers' Reactions to Uncertain Advice and Uncertain Promotions.

Gao, G., \& Gudykunst, W. B. (1990). Uncertainty, Anxiety, and Adaptation. International Journal of Intercultural Relations, 14, 301-317. https://doi.org/10.1016/0147-1767(90)90017-Q

Gneezy, U., List, J. A., \& Wu, G. (2006). The Uncertainty Effect: When a Risky Prospect Is Valued Less than Its Worst Possible Outcome. The Quarterly Journal of Economics, 121, 1283-1309. https://doi.org/10.1093/qje/121.4.1283

Goldsmith, K., \& Amir, O. (2010). Can Uncertainty Improve Promotions? Journal of Marketing Research, 47, 1070-1077. https://doi.org/10.1509/jmkr.47.6.1070

Gordon, K. (2003). The Impermanence of Being: Toward a Psychology of Uncertainty. Journal of Humanistic Psychology, 43, 96-117. https://doi.org/10.1177/0022167802250731

Greenwald, A. G. (1980). The Totalitarian Ego: Fabrication and Revision of Personal History. American Psychologist, 35, 603-618. https://doi.org/10.1037/0003-066X.35.7.603

Guo, Z., Zhang, Y., Zhang, Y. et al. (2019). The Degree of the Uncertain Reward and Customer Engagement: An Explanation Mechanism Based on Optimistic Estimation. Asia Pacific Journal of Marketing and Logistics, 32, 879-898. https://doi.org/10.1108/APJML-03-2019-0185

Hill, K. M., Fombelle, P. W., \& Sirianni, N. J. (2016). Shopping under the Influence of Curiosity: How Retailers Use Mystery to Drive Purchase Motivation. Journal of Business Research, 69, 1028-1034. https://doi.org/10.1016/j.jbusres.2015.08.015

Homer, P. M., \& Kahle, L. R. (1988). A Structural Equation Test of the Value-AttitudeBehavior Hierarchy. Journal of Personality and social Psychology, 54, 638-646. https://doi.org/10.1037/0022-3514.54.4.638

Hsee, C. K., \& Ruan, B. (2016). The Pandora Effect: The Power and Peril of Curiosity. Psychological Science, 27, 659-666. https://doi.org/10.1177/0956797616631733

Jones, A., Wilkinson, H. J., \& Braden, I. (1961). Information Deprivation as a Motivational Variable. Journal of Experimental Psychology, 62, 126-137. https://doi.org/10.1037/h0045333

Kaufmann, G. (2003). Expanding the Mood-Creativity Equation. Creativity Research Journal, 15, 131-135. https://doi.org/10.1080/10400419.2003.9651405

Knight, F. H. (2012). Risk, Uncertainty and Profit. North Chelmsford: Courier Corporation.

Kostis, A., \& Ritala, P. (2020). Digital Artifacts in Industrial Co-Creation: How to Use VR Technology to Bridge the Provider-Customer Boundary. California Management Review, 62, 125-147. https://doi.org/10.1177/0008125620931859

Kruk, M. R., Halasz, J., Meelis, W., \& Haller, J. (2004). Fast Positive Feedback between the Adrenocortical Stress Response and a Brain Mechanism Involved in Aggressive Behavior. Behavioral Neuroscience, 118, 1062-1070. https://doi.org/10.1037/0735-7044.118.5.1062 
Laran, J., \& Tsiros, M. (2013). An Investigation of the Effectiveness of Uncertainty in Marketing Promotions Involving Free Gifts. Journal of Marketing, 77, 112-123. https://doi.org/10.1509/jm.11.0255

Le Menestrel, M. (2001). A Process Approach to the Utility for Gambling. Theory and Decision, 50, 249-262. https://doi.org/10.1023/A:1010325930290

Lee, Y. H., \& Qiu, C. (2009). When Uncertainty Brings Pleasure: The Role of Prospect Imageability and Mental Imagery. Journal of Consumer Research, 36, 624-633. https://doi.org/10.1086/599766

Lerner, M. J. (1965). Evaluation of Performance as a Function of Performer's Reward and Attractiveness. Journal of Personality and Social Psychology, 1, 355-360. https://doi.org/10.1037/h0021806

Loewenstein, G. (1994). The Psychology of Curiosity: A Review and Reinterpretation. Psychological Bulletin, 116, 75-98. https://doi.org/10.1037/0033-2909.116.1.75

Loomes, G., \& Sugden, R. (1982). Regret Theory: An Alternative Theory of Rational Choice under Uncertainty. The Economic Journal, 92, 805-824. https://doi.org/10.2307/2232669

Lye, C. T., Ng, T. H., Lim, K. P. et al. (2020). Investor Protection and Market Reaction to Unusual Market Activity Replies. International Journal of Emerging Markets, Ahead of Print. https://doi.org/10.1108/IJOEM-10-2019-0859

MacLeod, A. K., Williams, M. G., \& Bekerian, D. A. (1991). Worry Is Reasonable: The Role in Pessimism about Future Personal Events. Journal of Abnormal Psychology, 100, 478-486. https://doi.org/10.1037/0021-843X.100.4.478

Mandel, N., \& Nowlis, S. M. (2008). The Effect of Making a Prediction about the Outcome of a Consumption Experience on the Enjoyment of That Experience. Journal of Consumer Research, 35, 9-20. https://doi.org/10.1086/527339

Mazar, N., Shampanier, K., \& Ariely, D. (2016). When Retailing and Las Vegas Meet: Probabilistic Free Price Promotions. Management Science, 63, 250-266.

https://doi.org/10.1287/mnsc.2015.2328

Moon, A., \& Nelson, L. D. (2019). The Uncertain Value of Uncertainty: When Consumers Are Unwilling to Pay for What They Like. https://doi.org/10.1287/mnsc.2019.3426

Morschheuser, B., Hamari, J., \& Maedche, A. (2019). Cooperation or Competition-When Do People Contribute More? A Field Experiment on Gamification of Crowdsourcing. International Journal of Human-Computer Studies, 127, 7-24. https://doi.org/10.1016/j.ijhcs.2018.10.001

Norton, M. I., Frost, J. H., \& Ariely, D. (2007). Less Is More: The Lure of Ambiguity, or Why Familiarity Breeds Contempt. Journal of Personality and Social Psychology, 92, 97-105. https://doi.org/10.1037/0022-3514.92.1.97

Nuryakin, C., \& Munro, A. (2019). Experiments on Lotteries for Shrouded and Bundled Goods: Investigating the Economics of Fukubukuro. The Japanese Economic Review, 70, 168-188. https://doi.org/10.1111/jere.12194

Presson, P. K., \& Benassi, V. A. (1996). Illusion of Control: A Meta-Analytic Review. Journal of Social Behavior and Personality, 11, 493.

Rabin, M. (2000). Risk Aversion and Expected-Utility Theory: A Calibration Theorem. Econometrica, 68, 1281-1292. https://doi.org/10.1111/1468-0262.00158

Raeva, D., Mittone, L., \& Schwarzbach, J. (2010). Regret Now, Take It Now: On the Role of Experienced Regret on Intertemporal Choice. Journal of Economic Psychology, 31, 634-642. https://doi.org/10.1016/j.joep.2010.04.006 
Ruan, B., Hsee, C. K., \& Lu, Z. Y. (2018). The Teasing Effect: An Underappreciated Benefit of Creating and Resolving an Uncertainty. Journal of Marketing Research, 55, 556-570. https://doi.org/10.1509/jmr.15.0346

Seaborn, K., \& Fels, D. I. (2015). Gamification in Theory and Action: A Survey. International Journal of Human-Computer Studies, 74, 14-31.

https://doi.org/10.1016/j.ijhcs.2014.09.006

Sevilla, J., \& Meyer, R. J. (2020). Leaving Something for the Imagination: The Effect of Visual Concealment on Preferences. Journal of Marketing, 84, 109-126. https://doi.org/10.1177/0022242919899393

Shen, L., Fishbach, A., \& Hsee, C. K. (2014). The Motivating-Uncertainty Effect: Uncertainty Increases Resource Investment in the Process of Reward Pursuit. Journal of Consumer Research, 41, 1301-1315. https://doi.org/10.1086/679418

Shen, L., Hsee, C. K., \& Talloen, J. H. (2018). The Fun and Function of Uncertainty: Uncertain Incentives Reinforce Repetition Decisions. Journal of Consumer Research, 46, 69-81. https://doi.org/10.1093/jcr/ucy062

Sielicka-Różyńska, M., Jerzyk, E., \& Gluza N. (2020). Consumer Perception of Packaging: An Eye-Tracking Study of Gluten-Free Cookies. International Journal of Consumer Studies, 1-14. https://doi.org/10.1111/ijcs.12600

Strack, F., \& Deutsch, R. (2006). Reflective and Impulsive Determinants of Consumer Behavior. Journal of Consumer Psychology, 16, 205-216. https://doi.org/10.1207/s15327663jcp1603_2

Taleb, N. N. (2007). The Black Swan: The Impact of the Highly Improbable. New York: Random House.

Tan, H., Akram, U., \& Sui, Y. (2019). An Investigation of the Promotion Effects of Uncertain Level Discount: Evidence from China. Asia Pacific Journal of Marketing and Logistics, 31, 957-979. https://doi.org/10.1108/APJML-05-2018-0191

Taylor, S. E., \& Brown, J. D. (1988). Illusion and Well-Being: A Social Psychological Perspective on Mental Health. Psychological Bulletin, 103, 193-210. https://doi.org/10.1037/0033-2909.103.2.193

Tversky, A., Kahneman, D., Slovic, S. P., \& Slovic, P. (1982). Judgment under Uncertainty: Heuristics and Biases. London: Cambridge University Press. https://doi.org/10.1017/CBO9780511809477

Tversky, A, \& Kahneman, D. (1992). Advances in Prospect Theory: Cumulative Representation of Uncertainty. Journal of Risk and Uncertainty, 5, 297-323. https://doi.org/10.1007/BF00122574

Tversky, A., \& Kahneman, D. (1979). Prospect theory: An Analysis of Decision under Risk. Econometrica, 47, 263-291. https://doi.org/10.2307/1914185

Von Neumann, J., \& Morgenstern, O. (1944). Theory of Games and Economic Behavior. Princeton: Princeton University Press.

Vosgerau, J., Wertenbroch, K., \& Carmon, Z. (2006). Indeterminacy and Live Television. Journal of Consumer Research, 32, 487-495. https://doi.org/10.1086/500478

Whitchurch, E. R., Wilson, T. D., \& Gilbert, D. T. (2011). “He Loves Me, He Loves Me Not...” Uncertainty Can Increase Romantic Attraction. Psychological Science, 22, 172-175. https://doi.org/10.1177/0956797610393745

White, K., \& McFarland, C. (2009). When Are Moods Most Likely to Influence Consumers' Product Preferences? The Role of Mood Focus and Perceived Relevance of Moods. Journal of Consumer Psychology, 19, 526-536. https://doi.org/10.1016/j.jcps.2009.05.004 
Wilson, T. D., Centerbar, D. B., Kermer, D. A. et al. (2005). The Pleasures of Uncertainty: Prolonging Positive Moods in Ways People Do Not Anticipate. Journal of personality and social psychology, 88, 5-21. https://doi.org/10.1037/0022-3514.88.1.5

Wu, G. (1999). Anxiety and Decision Making with Delayed Resolution of Uncertainty. Theory and Decision, 46, 159-199. https://doi.org/10.1023/A:1004990410083

Wucker, M. (2016). The Gray Rhino: How to Recognize and Act on the Obvious Dangers We Ignore. London: Macmillan.

$\mathrm{Xu}, \mathrm{H} ., \mathrm{Wu}, \mathrm{Y} ., \mathrm{Xi}, \mathrm{N} . \mathrm{N} .$, \& Hamari, J. (2019). What Determines the Successfulness of a Crowdsourcing Campaign? A Study on Attributes of Crowdsourcing Campaigns. Association for Information Systems (AMCIS), Virtual Communities and Collaboration (VCC).

Xu, Z., \& Dukes, A. (2019). Product Line Design under Preference Uncertainty Using Aggregate Consumer Data. Marketing Science, 38, 669-689. https://doi.org/10.1287/mksc.2019.1160

$\mathrm{Xu}, \mathrm{H}$. (2020). How to Gamify Online Business: A Case Study Based on “SMART” Model. Journal of Service Science and Management, 13, 516-534.

https://doi.org/10.4236/jssm.2020.133034 